\title{
Respiratory Physiotherapy in a Web Browser, Feasibility Study"
}

\author{
Matevz Leskovsek ${ }^{1 \#}$, Martin Lasič ${ }^{2}$, Dragomira Ahlin ${ }^{3}$ \\ ${ }^{1}$ BreathingLabs.com, Zdrav Dih d.o.o., Ljubljana, Slovenia \\ ${ }^{2}$ University Clinical Centre of Ljubljana, Ljubljana, Slovenia \\ ${ }^{3}$ Temza d.o.o., Ljubljana, Slovenia \\ Email: \#matevz.leskovsek@gmail.com, support@breathinglabs.com
}

Received August 4, 2013; revised September 5, 2013; accepted October 14, 2013

Copyright (C) 2013 Matevz Leskovsek et al. This is an open access article distributed under the Creative Commons Attribution License, which permits unrestricted use, distribution, and reproduction in any medium, provided the original work is properly cited.

\begin{abstract}
In this paper, feasibility of web based breathing exercises for respiratory rehabilitation is examined. A system included visual guidance in a web browser and a microphone equipped headset for biofeedback and interaction. Feasibility was assessed in a controlled environment on 34 subjects with anxiety disorders that were not offered any help from the personnel. Weak points of comprehensibility were identified as applying headset (21\%) and adhering to breathing exercises instructions (7\%). No adverse events were identified. Design flaws that correlated with poor user's experience were 1) the unpleasant feelings induced by watching the computer screen (21\%) and 2) ease/difficulty of physically applying headset (14\%). We conclude that conducting breathing exercises by using an acoustic microphone and a web browser is feasible and should be further researched. Additionally we conclude that audio feedback might be more pleasant to some people.
\end{abstract}

Keywords: COPD; Asthma; Respiratory Physiotherapy; Breathing Exercises

\section{Introduction}

Chronic obstructive pulmonary disease (COPD) is a chronic condition of breathing malfunction that occurs in longer lasting asthma, emphysema or chronic bronchitis [1-3]. Burden of COPD is best documented in US where the economic burden in 2007 was $\$ 42.6$ billion in health care costs and lost productivity. In 2006, global average of male and female population diagnosed with COPD was $9.8 \%$ and 5.6\%, respectively [4-7]. Breathing exercises are prescribed to patients in all stages of COPD [3]. The most commonly taught maneuver in such breathing exercises is exhalation through pursed lips commonly referred to as Pursed Lip Breathing (PLB). PLB is described in the American Thoracic Society guidelines as involving "a nasal inspiration followed by expiratory blowing against partially closed lips, avoiding forceful exhalation" [8,9]. PLB reduces breathing rate, helps make exhalation more efficient, reduces dyspnea (short-

*Declaration of Interest: Matevz Leskovsek is a partner at Zdrav dih d.o.o., a company that produces human computer interfaces for breathing exercises, breathing games, and breathing entertainment. Other authors declare no competing interests.

\#Corresponding author. ness of breath), and improves cellular oxygenation [913]. We hypothesize that it would be valuable to improve compliance of such exercises by providing guidance and supervision in a home setting. Objective of our research was to assess the feasibility of guiding users to perform breathing exercises by using an acoustic microphone positioned in front of user's mouth and visual guidance provided in a web browser. Trial included patients diagnosed with anxiety disorders as we reason that patients with anxiety disorders could identify most design flaws and comprehensibility issues of such a system. Feasibility was assessed by A) evaluating comprehensibility of proposed guidance system and identifying its weak points, $B$ ) identifying adverse events and $C$ ) identifying design flaws that correlate with poor user's experience.

\section{Materials and Methods}

Trial was conducted on four separate days within one month period. Volunteers that participated in the trial were active adults (34 subjects), that were consulting a medical doctor because of a career related burnout or similar stress related disorder and were diagnosed with 
either anxiety, stress related disorder or career related burnout. Trial was conducted at the psychiatric clinic TEMZA d. o. o. and had been approved by the Medical Ethics Committee of Slovenia (application number 120/ 02/10) on 24th March 2010. Prior to an experiment volunteers were asked to read and sign an informed consent that appeared at the top of the questionnaire. Personal information was not collected although some volunteers did identify themselves by their full name while some of them signed as anonymous. Volunteers were then asked to follow the instructions on the computer screen. The first instruction showed the following image (Figure 1) and asked volunteers to install the headset [14] accordingly. When clicking "next" volunteers were shown an animation (Figure 2).

Volunteers were required to accomplish 50 breathing cycles in order to complete the exercise. Then volunteers were asked to answer six questions by checking a YES/ NO checkmark (Table 1).

Additionally volunteers were encouraged to provide comments of their own choice.

Objective A)

Comprehensibility of guidance system was evaluated by questions \# 1 and \# 2. Its weak points were identified by observing which of those negative answers correlated with negative answers to questions \# 5 or \# 6. Additionally user provided comments were screened to identify those expressing comprehensibility issues of proposed technology. Those such comments that correlated with negative answers to questions \# 5 or \# 6 were also identified as comprehensibility's weak points.

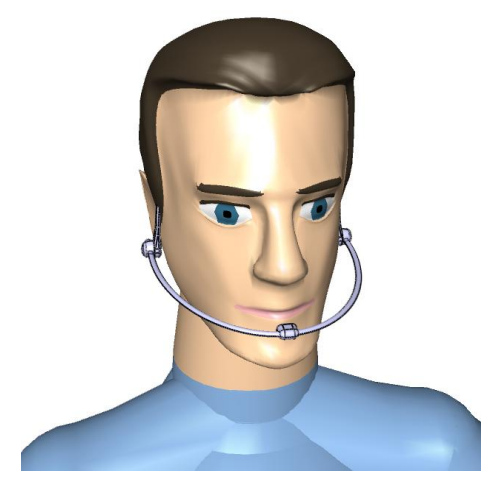

Figure 1. Image shown to volunteers when asked to apply the headset.

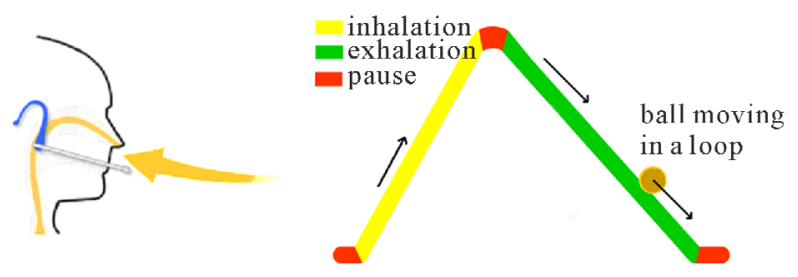

Figure 2. Animation guidance used in breathing exercises.
Table 1. Questionnaire used in a trial.

\begin{tabular}{|c|c|c|}
\hline Objective & Question & Options \\
\hline \multirow{2}{*}{$\mathbf{A}$} & $\begin{array}{l}\# 1 \text { Are computer's instructions for conducting } \\
\text { breathing easy enough to understand? }\end{array}$ & YES/NO \\
\hline & $\begin{array}{l}\text { \#2 Do you think that one can use the device } \\
\text { without the help of a therapist? }\end{array}$ & YES/NO \\
\hline \multirow{2}{*}{ B } & $\begin{array}{l}\text { \#3 Is the use of device painful or unpleasant } \\
\text { in any way? }\end{array}$ & YES/NO \\
\hline & $\begin{array}{l}\text { \#4 Were the breathing exerciseS painful or } \\
\text { uncomfortable in any way? }\end{array}$ & YES/NO \\
\hline \multirow{2}{*}{ C } & $\begin{array}{l}\text { \#5 Do you think that you have achieved } \\
\text { deeper breathing and consequently greater } \\
\text { relaxation? }\end{array}$ & YES/NO \\
\hline & $\begin{array}{l}\text { \#6 Would you recommend such computer } \\
\text { based breathing exercises to your friends if } \\
\text { you were positive that it is helpful to them? }\end{array}$ & YES/NO \\
\hline
\end{tabular}

\section{Objective B)}

Adverse events were evaluated by answers to questions \#3 and \#4. Additionally user provided comments were screened to identify those that expressed unpleasant feelings of any kind, and if found were included as adverse events.

\section{Objective C)}

Design flaws that correlate with poor user's experience were assessed by identifying which answers to questions \#1, \#2, \#3, and \#4 correlate with negative answers to questions \#5 or \#6. Additionally all comments that correlate with negative answers to questions \#5 or \#6 were identified as design flaws.

\section{Results}

Minimum 7 volunteers and maximum 10 volunteers participated in a trial each day. Each volunteer participated in a trial only once and none of them was withdrawn from the trial. All volunteers answered all the questions in the questionnaire. The results are shown in Table 2.

Weak points of comprehensibility are A1) applying headset (21\%) and A2) adhering to breathing exercises instructions (7\%). B) No adverse events are identified. C) Design flaws that correlate with poor user's experience are C1) the unpleasant feeling induced by watching the computer screen (21\%) and C2) ease/difficulty of physically applying headset (14\%).

\section{Discussion}

Other devices for breathing exercises require users to force air into device, such as Frolov device (Dinamika LTD, Russia), [15-19] PowerLung (Powerlung inc.) [20], SpiroBall/ThreeBall (Leventon Barcelona ${ }^{1}$ ) [21], and Threshold PEEP/IMT (Respironics Healthscan Inc. ${ }^{2}$ ), [22]. Using acoustic microphone positioned in front of

\footnotetext{
${ }^{1}$ Aquired by Werfen Corporation.

${ }^{2}$ Aquired by Siemens Corporation.
} 
Table 2. Results of the trial.

\begin{tabular}{|c|c|c|c|c|c|c|c|c|}
\hline & Day & Day I & Day II & Day III & Day IV & Summary & Summary & Summary \\
\hline & $\begin{array}{l}\text { Number of } \\
\text { volunteers }\end{array}$ & 9 & 10 & 8 & 7 & 34 & 34 & 34 \\
\hline Objective & Question & $\begin{array}{l}\text { Positive } \\
\text { answers }\end{array}$ & $\begin{array}{l}\text { Positive } \\
\text { answers }\end{array}$ & $\begin{array}{l}\text { Positive } \\
\text { answers }\end{array}$ & $\begin{array}{l}\text { Positive } \\
\text { answers }\end{array}$ & $\begin{array}{l}\text { Positive } \\
\text { answers }\end{array}$ & By objective & $\begin{array}{c}\text { Correlation } \\
\text { with \#5 and \#6 }\end{array}$ \\
\hline \multirow{2}{*}{ A } & $\# 1$ & $\begin{array}{c}8 / 9 \\
(89 \%)\end{array}$ & $\begin{array}{c}8 / 10 \\
(80 \%)\end{array}$ & $\begin{array}{c}8 / 8 \\
(100 \%)\end{array}$ & $\begin{array}{c}6 / 7 \\
(86 \%)\end{array}$ & $\begin{array}{l}30 / 34 \\
(88 \%)\end{array}$ & \multirow{2}{*}{$\begin{array}{c}\text { Positive reply } \\
\text { to \#1 and \#2 } \\
\text { (88\%) }\end{array}$} & $50 \%$ \\
\hline & $\# 2$ & $\begin{array}{c}8 / 9 \\
(89 \%)\end{array}$ & $\begin{array}{c}8 / 10 \\
(80 \%)\end{array}$ & $\begin{array}{c}8 / 8 \\
(100 \%)\end{array}$ & $\begin{array}{c}7 / 7 \\
(100 \%)\end{array}$ & $\begin{array}{l}31 / 34 \\
(91 \%)\end{array}$ & & $100 \%$ \\
\hline \multirow{2}{*}{ B } & \#3 & $\begin{array}{c}3 / 9 \\
(33 \%)\end{array}$ & $\begin{array}{l}2 / 10 \\
(20 \%)\end{array}$ & $\begin{array}{c}3 / 8 \\
(37 \%)\end{array}$ & $\begin{array}{c}1 / 7 \\
(14 \%)\end{array}$ & $\begin{array}{c}9 / 34 \\
(26 \%)\end{array}$ & \multirow{2}{*}{$\begin{array}{l}\text { Negative reply } \\
\text { to \#3 or \#4 } \\
(23 \%)\end{array}$} & $100 \%$ \\
\hline & \#4 & $\begin{array}{c}3 / 9 \\
(33 \%)\end{array}$ & $\begin{array}{c}3 / 10 \\
(30 \%)\end{array}$ & $\begin{array}{c}2 / 8 \\
(25 \%)\end{array}$ & $\begin{array}{c}0 / 7 \\
(0 \%)\end{array}$ & $\begin{array}{c}8 / 34 \\
(23 \%)\end{array}$ & & $100 \%$ \\
\hline \multirow{2}{*}{ C } & $\# 5$ & $\begin{array}{c}4 / 9 \\
(44 \%)\end{array}$ & $\begin{array}{c}6 / 10 \\
(60 \%)\end{array}$ & $\begin{array}{c}5 / 8 \\
(62 \%)\end{array}$ & $\begin{array}{c}5 / 7 \\
(71 \%)\end{array}$ & $\begin{array}{l}20 / 34 \\
(59 \%)\end{array}$ & \multirow{2}{*}{$\begin{array}{c}\text { Positive reply } \\
\text { to \#5 and \#6 } \\
\text { (59\%) }\end{array}$} & $\mathrm{n} / \mathrm{a}$ \\
\hline & $\# 6$ & $\begin{array}{c}9 / 9 \\
(100 \%)\end{array}$ & $\begin{array}{c}10 / 10 \\
(100 \%)\end{array}$ & $\begin{array}{c}8 / 8 \\
(100 \%)\end{array}$ & $\begin{array}{c}7 / 7 \\
(100 \%)\end{array}$ & $\begin{array}{c}34 / 34 \\
(100 \%)\end{array}$ & & $\mathrm{n} / \mathrm{a}$ \\
\hline
\end{tabular}

user's mouth has some obvious advantages over these devices. Firstly, blowing air into the microphone does not require physical contact with users' mouth or lips. Therefore it provides fewer possibilities for infection. Secondly, using a microphone to assess the user's breathing allows for the greatest possible interoperability with other electronic devices that have audio input codecs already implemented, such as mobile phones, tablets and portable music players. It thus allows for low cost integration with various computer games and other multimedia content to improve user's experience and improve motivation for conducting breathing exercises. Thirdly, using a web browser to conduct breathing exercises allows for the best possible supervision of exercise implementation and can be used in various telemedicine applications. Additionally, the proposed technology provides one major advantage; user can be eventually taught to implement the exhalation through pursed lips into their daily routine and change their breathing behavior without raising their dependence on technology. Such a behavior can already be observed in humans, for example, when a person exhales through pursed lips as a sign of relief. Some devices do not require a user to exhale against pressure, such as Resperate device (Intercure Ltd) [23-27] and so it has fewer benefits for COPD patients.

We conclude that conducting pursed lip breathing exercises by using an acoustic microphone in front of user's mouth is feasible and should be further researched. Additionally we conclude that audio feedback might be more pleasant to some people.

\section{Acknowledgements}

This research was supported by the European Union through the European Social Fund and was coordinated by the Public Agency for Technology of the Republic of
Slovenia (TIA) according to the program of Human Resources Development 2007-2013.

\section{REFERENCES}

[1] F. E. Hargreave and K. Parameswaran, "Asthma, COPD and Bronchitis Are Just Components of Airway Disease," European Respiratory Journal, Vol. 28, No. 2, 2006, pp. 264-267. http://dx.doi.org/10.1183/09031936.06.00056106

[2] B. R. Celli, W. MacNee, A. Agusti, A. Anzueto, B. Berg, A. S. Buist, et al., "Standards for the Diagnosis and Treatment of Patients with COPD: A Summary of the ATS/ ERS Position Paper,” European Respiratory Journal, Vol. 23, No. 6, 2004, pp. 932-946. http://dx.doi.org/10.1183/09031936.04.00014304

[3] K. F. Rabe, S. Hurd, A. Anzueto, P. J. Barnes, S. A. Buist, P. Calverley, et al., "Global Strategy for the Diagnosis, Management, and Prevention of Chronic Obstructive Pulmonary Disease: GOLD Executive Summary,” American Journal of Respiratory and Critical Care Medicine, Vol. 176, No. 6, 2007, p. 532. http://dx.doi.org/10.1164/rccm.200703-456SO

[4] J. D. Miller, T. Foster, L. Boulanger, M. Chace, M. W. Russell, J. P. Marton, et al., "Direct Costs of COPD in the U.S.: An Analysis of Medical Expenditure Panel Survey (MEPS) Data," COPD: Journal of Chronic Obstructive Pulmonary Disease, Vol. 2, No. 3, 2005, pp. 311-318. http://dx.doi.org/10.1080/15412550500218221

[5] R. J. Halbert, J. L. Natoli, A. Gano, E. Badamgarav, A. S. Buist and D. M. Mannino, "Global Burden of COPD: Systematic Review and Meta-Analysis,” European Respiratory Journal, Vol. 28, No. 3, 2006, p. 523. http://dx.doi.org/10.1183/09031936.06.00124605

[6] E. Nabel, "Morbidity and Mortality: 2007 Chart Book on Cardiovascular, Lung and Blood Diseases,” National Heart, Lung and Blood Institute.

[7] C. D. Mathers and D. Loncar, "Projections of Global 
Mortality and Burden of Disease from 2002 to 2030,” PLOS Medicine, Vol. 3, No. 11, 2006, p. e442. http://dx.doi.org/10.1371/journal.pmed.0030442

[8] C. P. Van der Schans, W. De Jong, E. Kort, P. J. Wijkstra, G. H. Koeter, D. S. Postma, et al., "Mouth Pressures during Pursed Lip Breathing," Physiotherapy Theory and Practice, Vol. 11, No. 1, 1995, pp. 29-34. http://dx.doi.org/10.3109/09593989509022395

[9] E. H. Breslin, "The Pattern of Respiratory Muscle Recruitment during Pursed-Lip Breathing,” Chest, Vol. 101, No. 1, 1992, p. 75. http://dx.doi.org/10.1378/chest.101.1.75

[10] G. A. De FFregonezi, V. R. Resqueti and R. G. Rous, "Pursed Lips Breathing," Archivos de Bronconeumologia, Vol. 40, No. 6, 2004, pp. 279-282. http://dx.doi.org/10.1016/S1579-2129(06)70099-4

[11] A. L. Barach, "Physiologic Advantages of Grunting, Groaning, and Pursed-Lip Breathing: Adaptive Symptoms Related to the Development of Continuous Positive Pressure Breathing," Bulletin of the New York Academy of Medicine, Vol. 49, No. 8, 1973, p. 666.

[12] R. Garrod and T. Mathieson, "Pursed Lips Breathing Are We Closer to Understanding Who Might Benefit?” Chronic Respiratory Disease, Vol. 10, No. 1, 2013, pp. 3-4. http://dx.doi.org/10.1177/1479972312472689

[13] J. Roa, S. Epstein, E. Breslin, T. Shannon and B. Celli, "Work of Breathing and Ventilatory Muscle Recruitment during Pursed Lip Breathing in Patients with Chronic Airway Obstruction,” American Review of Respiratory Disease, Vol. 143, 1991, p. A77.

[14] M. Leskovsek, D. Ahlin, R. Cancer, M. Hosta, D. Enova, N. Pusenjak, et al., "Low Latency Breathing Frequency Detection and Monitoring on a Personal Computer," Journal of Medical Engineering \& Technology, Vol. 35, No. 6-7, 2011, pp. 322-329. http://dx.doi.org/10.3109/03091902.2011.591481

[15] M. A. Khan, "Clinical Trial 'Application of an Individual Inhaler-Training Device in Cases of Breathing Disorders and Vegetal Vascular Dystonia in Children'," Federal State Institution Scientific Centre of Restorative Medicine and Balneology Roszdrav, Scientific Centre of Restorative Medicine, Moscow, 2004.

[16] S. Medvedeva, "Clinical Trial for Individual Simulator Inhaler,” Introduced by Dinamika LTD, 2004.

[17] N. P. Bahtina, "Clinical Trial of the Individual InhalerTraining Device Produced by the 'Dinamika' Company,” 2004.
[18] V. P. Lozovskaya, “Clinical Trial Protocol of Individual Inhaler-Training Device Produced by the 'Dinamika' Company," Clinic of Scientific Centre of Clinical and Experimental Medicine Siberian Branch of the Russian Medical Academy, 2004.

[19] V. A. Epofanov and I. A. Baukina, "Rationale for Application of Individual Inhaler-Training Device in System of Rehabilitation," Moscow State Medical-Dentistry University, Moscow, 2006.

[20] L. Lloyd and S. Marcos, "Respiratory Resistance Training on Sleep Quality in Persons with Spinal Cord Injury," Texas State University, San Marcos, 2008.

[21] A. Munshi, “A Prospective Study of Variation in Breath Holding Times at Various Phases of Respiration during the Course of Radiotherapy Including the Effect of Respiratory Training in Lung Cancer Patients,” Tata Memorial Hospital, 2011.

[22] D. Martin, "Inspiratory Muscle Strength Training Improves Weaning Outcome in Failure to Wean Patients: A Randomized Trial,” Critical Care, Vol. 15, 2011, p. R84. http://dx.doi.org/10.1186/cc10081

[23] B. Gavish, "Device-Guided Breathing in the Home Setting: Technology, Performance and Clinical Outcomes," Biological Psychology, Vol. 84, No. 1, 2010, pp. 150-156. http://dx.doi.org/10.1016/j.biopsycho.2010.02.013

[24] W. J. Elliott and J. L. Izzo Jr., “Device-Guided Breathing to Lower Blood Pressure: Case Report and Clinical Overview," Medscape General Medicine, Vol. 8, No. 3, 2006, p. 23.

[25] G. Parati and R. Carretta, "Device-Guided Slow Breathing as a Non-Pharmacological Approach to Antihypertensive Treatment: Efficacy, Problems and Perspectives," Journal of Hypertension, Vol. 25, No. 1, 2007, p. 57. http://dx.doi.org/10.1097/HJH.0b013e328012bf0f

[26] R. Viskoper, I. Shapira, R. Priluck, R. Mindlin, L. Chornia, A. Laszt, et al., "Nonpharmacologic Treatment of Resistant Hypertensives by Device-Guided Slow Breathing Exercises," American Journal of Hypertension, Vol. 16, No. 6, 2003, pp. 484-487. http://dx.doi.org/10.1016/S0895-7061(03)00571-5

[27] M. H. Schein, B. Gavish, T. Baevsky, M. Kaufman, S. Levine, A. Nessing, et al., "Treating Hypertension in Type II Diabetic Patients with Device-Guided Breathing: A Randomized Controlled Trial," Journal of Human Hypertension, Vol. 23, No. 5, 2008, pp. 325-331. http://dx.doi.org/10.1038/jhh.2008.135 